\title{
Evaluation of Flow Capture Techniques for Measuring HVAC Grille Airflows
}

\author{
lain S. Walker, Ph.D. \\ ASHRAE Member
}

\author{
Craig P. Wray, P.Eng. \\ ASHRAE Member
}

\begin{abstract}
This paper discusses the accuracy of commercially available flow hoods for residential applications. Results of laboratory and field tests indicate these hoods can be inadequate to measure airflows in residential systems, and there can be large measurement discrepancies between different flow hoods. The errors are due to poor calibrations, sensitivity of the hoods to grille airflow non-uniformities, and flow changes from added flow resistance. It is possible to obtain reasonable results using some flow hoods if the field tests are carefully done, the grilles are appropriate, and grille location does not restrict flow hood placement. We also evaluated several simple flow capture techniques for measuring grille airflows that could be adopted by the HVAC industry and homeowners as simple diagnostics. These simple techniques can be as accurate as commercially available devices. Our test results also show that current calibration procedures for flow hoods do not account for field application problems. As a result, agencies such as ASHRAE or ASTM need to develop a new standard for flow hood calibration, along with a new measurement standard to address field use of flow capture techniques.
\end{abstract}

\section{INTRODUCTION}

For many years, the HVAC industry has used flow hoods to measure grille airflows in non-residential buildings, usually as part of a testing and balancing procedure; residential HVAC systems very rarely have been tested (usually by the research community). Now, utility programs, weatherization programs, and codes and standards such as California's Title 24 are beginning to consider the need to commission residential HVAC systems. Such efforts include using flow hoods to determine if individual rooms are getting correct airflow, and to estimate total airhandler airflow and duct air leakage.

A few studies have evaluated flow hood measurement uncertainty in commercial applications (Choat 1999); they found that flow hoods are poor at measuring commercial grille flows. Previous studies by LBNL (Walker et al. 2001, Wray et al. 2002) examined the uncertainty associated with using flow hoods to measure residential grille airflows. The results showed that some commercially available hoods can be inadequate for measuring flows in residential systems, and that active flow hoods equipped with measurement devices that are insensitive to grille airflow patterns give reliable and consistent results. This is primarily because of their sensitivity to flow nonuniformities and the difficulty in accounting for insertion losses on multiple low-pressure branch systems.

This paper compiles the results of recent studies at LBNL that evaluated additional commercially available flow capture devices as well as several non-commercialized techniques. We evaluated the various devices and measurement techniques under both laboratory and field conditions, using both single and multiple branch system tests. The laboratory tests enabled us to examine detailed performance characteristics and sensitivity to various measurement technique issues such as the critical centering of flow capture devices over grilles. In particular, the single branch laboratory tests allowed us to compare the flow capture measurements to very precise airflow references. These single branch tests are similar to the methods used by manufacturers to calibrate their flow hoods. The multi-branch tests in the laboratory and field allowed us to study the insertion loss effects on flow hood performance. Insertion losses occur when the flow resistance of a capture device significantly changes the flow through an individual grille. Residential systems are particularly sensitive to this issue because grilles are placed at the end of short branches (with correspondingly low pressure drops) such that the extra flow resistance of the capture device reduces the airflow through the grille being measured and redirects some of the airflow to other grilles in the system. Our tests of the multi-branch systems in the laboratory and field used an active flow hood as a reference. That hood has been shown to be accurate for a broad range of applications in previous studies (Walker et al. 2001, Wray et al. 2002).

In addition to evaluating the performance of the capture techniques for measuring residential grille airflows, we also carried out some field measurements on commercial grilles. We had speculated in our previous studies that many of the failings of commercially available devices would be reduced when they are used for commercial 
systems because the grilles on those systems are usually larger (they fill the whole cross section of the flow capture device) and some have more uniform flow due to the presence of perforated plate diffusers on the grilles. To provide some baseline data on the ability of the commercially available flow hoods to measure airflows for commercial grilles, we used several of these devices to measure supply airflows at several grilles in a large commercial building, using the active flow hood as the reference.

When evaluating the accuracy of the flow hoods we need to keep in mind that there is a range of potential applications for flow hoods requiring different levels of accuracy. Table 1 summarizes typical accuracy requirements for different residential diagnostic applications. Walker et al. (2001) describe these accuracy requirements in more detail.

Table 1. Summary of Accuracy Requirements for Residential Flow Hood Applications

\begin{tabular}{|l|c|}
\hline Application & Required Minimum Accuracy \\
\hline Identifying large leaks/disconnected ducts & $\pm 50 \%$ \\
\hline Identifying room to room pressure imbalances & $\pm 25 \%$ \\
\hline Ensuring room load and comfort requirements are met & $\pm 20 \%$ \\
\hline $\begin{array}{l}\text { Determining air handler flow for cooling equipment } \\
\text { performance estimation }\end{array}$ & $\pm 10 \%$ \\
\hline Determining overall system flow imbalances & $\pm 10 \%$ \\
\hline Determining duct leakage & $\pm 3 \%$ \\
\hline
\end{tabular}

\section{TESTED FLOW CAPTURE TECHNIQUES}

\section{Commercially Available Capture Devices}

A total of eight commercially available flow capture devices for measuring grille airflows were tested in this study. Most use some sort of built-in time averaging to reduce the influence of flow and pressure fluctuations. A typical averaging period is on the order of five to ten seconds. The devices that we tested can be split into three broad classifications.

Standard flow hoods use a fabric hood that is fixed to a rigid frame that fits over the grille. The fabric hood directs the flow over a velocity or pressure-drop sensing element. Most of these devices have built-in electronic signal processing and information displays that include the ability to perform time averaging, temperature compensation, and variable insertion loss correction. However, some use analog gauges to display the flow, have no temperature compensation, and have a fixed insertion loss correction. We evaluated five different flow hoods in these studies.

Active flow hoods use a flow capture device connected to a calibrated fan-flow meter. A length of plastic flex duct and a flow straightener placed between the flow capture device and the fan-flow meter make this device insensitive to non-uniform flows at the grille. Adjusting the fan of the calibrated fan-flow meter until there is no pressure difference between the room and the hood compensates for the flow resistance of the capture hood, flexible duct, and flowmeter. This pressure balancing procedure ensures that placing the flow hood over the grille does not reduce the flow out of the grille.

The pressure inside the hood is measured using a soaker hose (normally used to water plants) sewn to the perimeter of the flow capture hood about half way along its length. This hose has many small holes that effectively average pressures over the whole length of the hose, and therefore over a large fraction of the hood wall. Laboratory tests using several hood pressure measurement techniques have shown that the precise method and location of hood pressure measurement is not critical; the test results showed a spread of less than $2 \%$. However, all the results presented here used the soaker hose for consistency and because it resulted in the least bias on our full-scale duct system laboratory.

The device is not commercially available as a complete package; however, many practitioners have the fan-flow meter device used in these tests. Because laboratory results (Walker et al. 2001, Wray et al. 2002) showed this flow hood to be very accurate, it was used as the reference flow hood for the multi-branch laboratory and field studies.

Flow horns use a formed rigid glass fiber housing to capture the flow and direct the airflow over a thermal anemometer. The housing cross section varies from rectangular at the entry to round at the exit where the anemometer is mounted. These flow horns came with anemometers that are specially calibrated for use with these particular flow horns. They were therefore able to provide measurements directly in airflow (rather than just a 
velocity). There are also flow horns from other manufacturers (that we did not test) that use vane anemometers in the throat of similar rigid flow capture devices.

\section{Alternative Flow Capture Techniques}

Because our previous studies (Walker et al. 2001, Wray et al. 2002, Sherman et al. 2002) found that many existing measurement techniques and devices performed poorly when measuring residential grilles, we examined two alternative flow capture techniques. Another reason for considering alternative techniques is that the residential HVAC industry needs simpler and less expensive measurement methods in order for diagnostics to become more widespread. Therefore, the techniques we considered were focused on reducing the cost and complexity of diagnostic testing. Furthermore, inspired by the CMHC (2002) approach to having homeowners perform simple selfevaluations of their houses (particularly of their heating and cooling systems), we selected techniques that could easily be performed by a homeowner using rudimentary equipment and skills. We hope that providing homeowners with these sorts of tools will enable them to make better-informed choices about their HVAC systems.

"Basket" Hood: The basket hood uses a calibrated flow resistance to measure the flow through HVAC system grilles. Specifically, this hood measures the airflow by a pressure drop through a set of calibrated holes in the sides of the basket. There are commercially available flow resistance devices that use the same principle for measuring exhaust fan airflows, but we did not test them in this study.

We found that normal household laundry baskets tend to have uniform holes and are well-suited to this application. However, most laundry baskets have too many holes (and therefore too little flow resistance) for a pressure difference between the basket and the room to be measured reliably. Therefore, we systematically covered the holes in the sides of the basket. We optimized the position of the holes for the type of grilles (supply or return), because we found that holes too close to the flow entry have increased sensitivity to flow non-uniformity. The number and size of the holes have also been optimized to produce a reasonably accurate pressure signal while minimizing the backpressure effects.

Different sized basket hoods were developed for supplies and returns because return grilles are often bigger than supply grilles and because many systems have fewer returns than supplies resulting in bigger airflows for each return. Returns are also easier to measure because the flow into the measuring device does not have the flow nonuniformities common to supply grilles.

The basket hoods that we developed incorporate two innovations to further reduce flow non-uniformity effects:

1. A "soaker" hose is fixed on the inside back of the basket and senses the static pressure inside the basket. This hose effectively averages pressures over a large fraction of the basket bottom.

2. A mesh screen is inserted in the entry of the basket and acts as a diffuser screen to reduce flow nonuniformities.

Figure 1 is an illustration of one of our prototype basket flow hoods. For use on commercial grilles, we added a commercially available flow capture hood to the inlet of the basket.
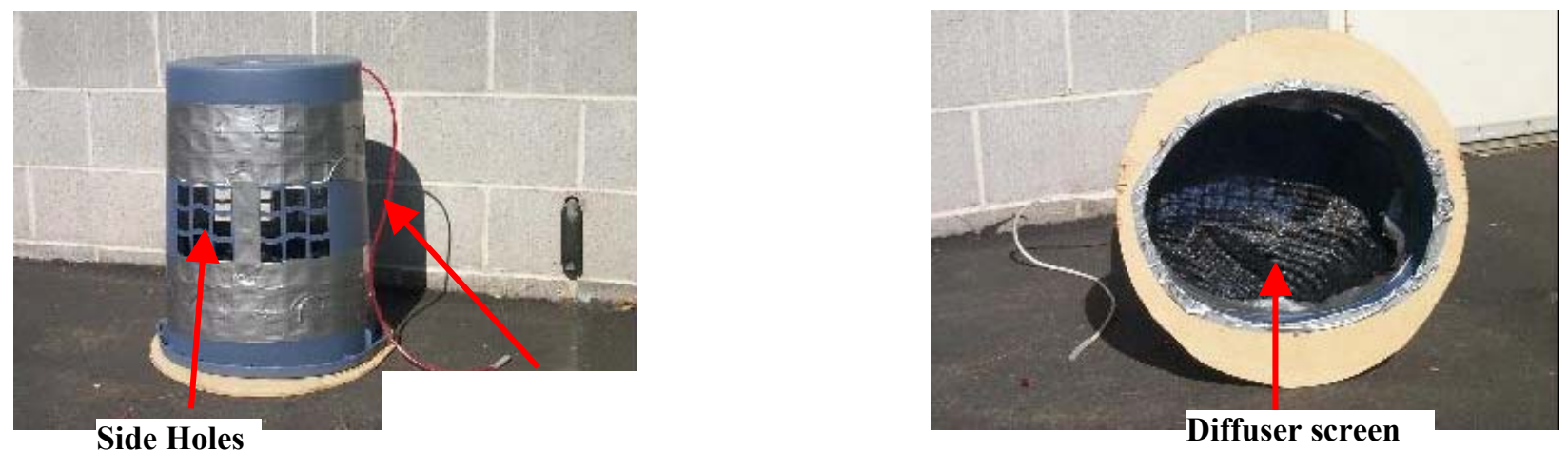

Figure 1. Supply basket hood

Because the flow resistance of the baskets was unknown, we calibrated them using a high accuracy $( \pm 0.5 \%)$ flow nozzle. The specifications required to measure the pressure difference with sufficient accuracy ( $0.1 \mathrm{~Pa}$ precision and time averaging facility) requires a relatively expensive pressure sensor (about \$500). Because of this requirement, we expect that this flow technique is more appropriate for HVAC or weatherization contractors rather than homeowners. We tested a total of five supply hoods and a single return hood, each with a different number of open holes (from 4 to 48 holes). Two different baskets were used: a Blue basket with three hole configurations and a 
White basket with two hole configurations. The basket/hole combinations are labeled in increasing number of holes: Blue 4, White 8, Blue 16, White 24, Blue 48.

Bag Filling: If only a rough estimate of grille flows is required, filling a bag to estimate flows is a very inexpensive and simple alternative to expensive commercially available flow hoods. For example, CMHC (2002) explains how to use an empty garbage bag to measure grille flows, in language suitable for homeowners. The measurement principle is very simple. A garbage bag is placed over the grille and the time required to fill the bag is measured using a stopwatch. Because the volume of the bag is known, we can determine the flow by dividing the volume by the time. This method is particularly applicable to homeowner diagnostics because no expensive equipment (like the pressure sensor for the basket hood) is needed. It also has the advantage that it gives a direct volumetric flow without relying on flow measurement techniques that only sample part of the flow or assume a degree of flow uniformity as with almost all of the other techniques. In addition, as a demonstration of high or low flow to homeowners (or builders/HVAC contractors), the bag filling has a direct visual element that is very appealing.

Originally, bags were used as a way of quickly checking for HVAC system problems that did not require a flow to be measured to better than about $30 \%$ accuracy. One of our aims in this study is to quantify the uncertainties associated with this method and to find ways to improve the measurement accuracy through simple techniques. After some experimentation, we implemented two improvements to the method to make the measurements more accurate and more repeatable. One improvement was adding a wood frame to the bag opening. This wood frame ensured that the bag kept its shape and gave a flat surface for easier edge sealing. The other improvement was adopting a measurement technique that helped to ensure consistent timing. Specifically, the user empties the bag and then places a sheet of cardboard over the bag opening, between the wood frame and the grille (as shown in Figure 2). This assembly is placed close to the grille without blocking the flow. The cardboard is then rapidly pulled away, and the frame of the bag opening is pressed around the grille. The use of the cardboard sheet introduces a rapid bag opening, and the sound of the wood frame contacting the surfaces around the grille gives a consistent audible stimulus to begin timing. For most airflows, the bag "pops" into its final shape (as illustrated in Figure 2), but for lower flows it is less easy to determine when the bag is "full". We also used a wire frame (made from coat hangers) and tested it on a range of entry shapes. The same calibration technique was used for the bags as for the baskets. A total of five bags were tested of different sizes and plastic film thickness.
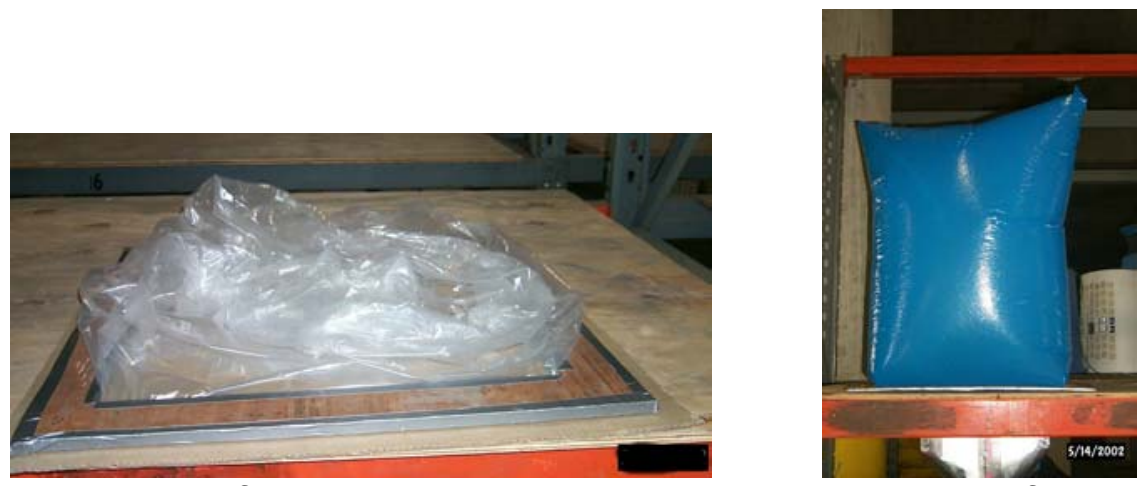

Figure 2. A clear bag before a measurement and a blue bag at the end of a measurement

\section{OVERVIEW OF LABORATORY TEST APPARATUSES}

\section{Single-Branch Laboratory Test Apparatus}

Figure 3 shows a schematic of the laboratory test apparatus that represents a "single branch" system in which all flow passes through the reference nozzle and the flow hood. The reference nozzle combines a flow straightener, a nozzle, and a pitot-averaging-array to form a flow meter that has an accuracy of $\pm 0.5 \%$ of the flow reading. We used an adjustable fan to produce a range of typical residential grille flows through the apparatus: 25 to $120 \mathrm{~L} / \mathrm{s}$ (53 to $250 \mathrm{cfm})$ for supplies and up to $1,000 \mathrm{~L} / \mathrm{s}(2,000 \mathrm{cfm})$ for returns. We changed the flow pattern entering the hoods by varying hood lateral placement relative to the grille (center, corner, and center edge), and by using different grille styles (Figure 4), different grille damper settings, and different boot types. 


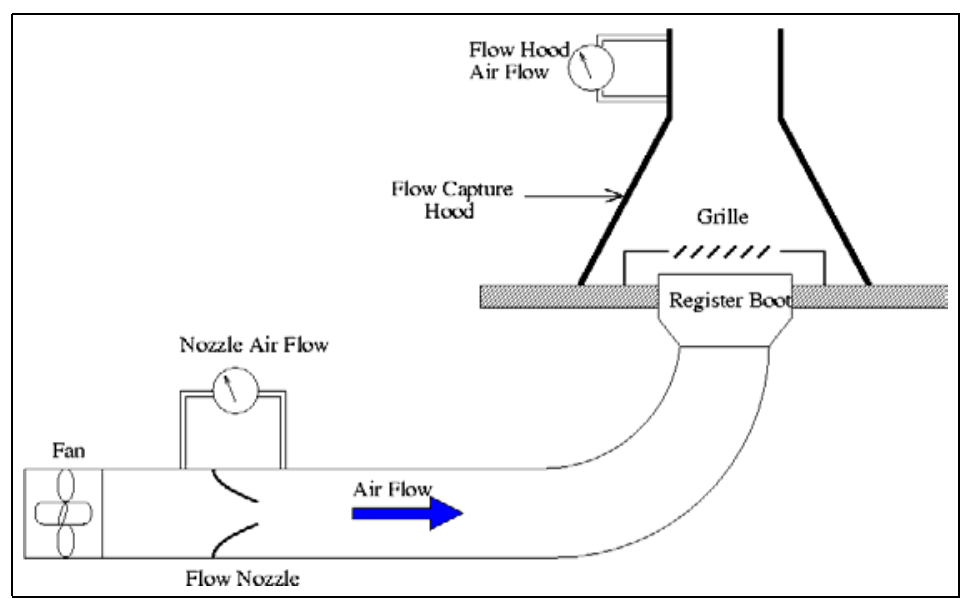

Figure 3. Single-branch grille airflow measurement apparatus
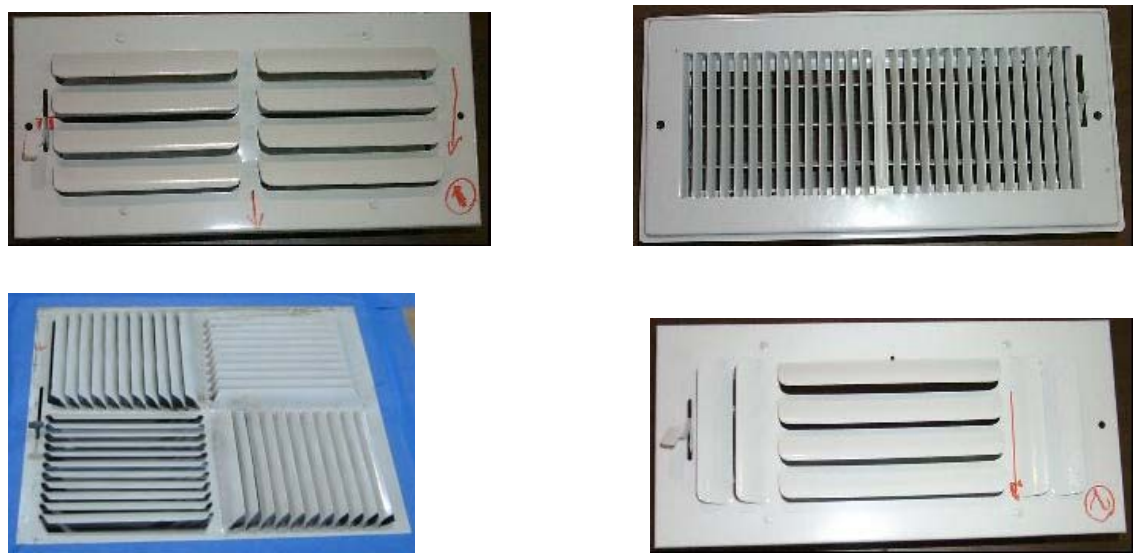

Figure 4. Examples of grilles used for single-branch calibration test apparatus. Clockwise from top left: one-way, two-way, three-way, and four-way throws.

\section{Multi-Branch Laboratory Test Apparatus}

The multi-branch laboratory tests used a full-scale duct system that is representative of a typical California duct system. It has a single return and eleven supply grilles, with a total flow of about $564 \mathrm{~L} / \mathrm{s}(1,200 \mathrm{cfm})$. The ducts are constructed from standard insulated flex duct with duct board splitter boxes at the duct branches. The ducts are suspended below a plywood deck (as if in a crawlspace). Abushakra et al. (2002) describe more details about this apparatus. All the grilles are the same size $(400 \mathrm{~mm} \times 190 \mathrm{~mm}, 15.5 " \times 7.5 ")$; an example is shown in Figure 5 . These grilles have a much more uniform and non-directional flow than those shown in Figure 4 because of the design of the grille. This means that the majority of differences between different flow measurement techniques can be attributed to poor centering over the grille and to insertion loss issues rather than the highly directional inhomogeneous flow from the grilles in Figure 4. The reference flow for each grille was determined using the active flow hood. Due to small changes in duct and splitter box location as the various experiments were carried out in the facility we found that the flows through a couple of the grilles changed by a few percent. Because the flow hoods were tested over a period of a year on this system, we measured the reference flows before each set of flow hood measurements to ensure that we accounted for these small changes. In addition, a large flow nozzle was used to continuously monitor the total flow for the system in all experiments. This continuous monitoring showed that insertion losses had no measurable (within the $\pm 0.5 \%$ accuracy of the flow nozzle) effect on the total flow. This indicates that flow reduction through the grille being measured appears at other grilles in the system. 


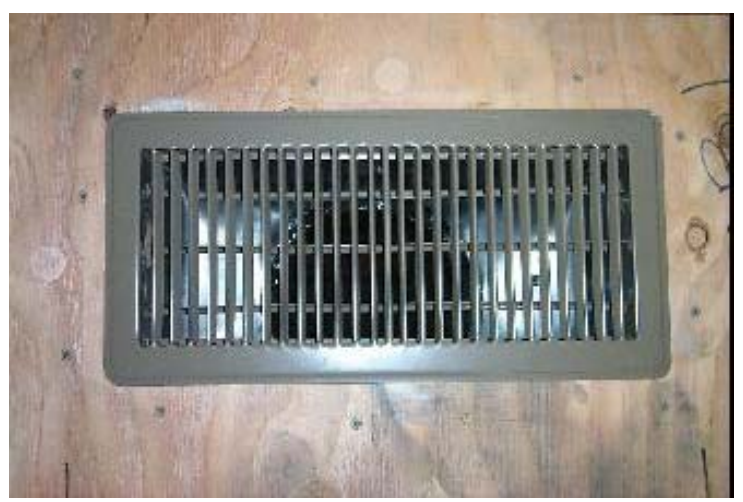

Figure 5. Example supply grille of multi-branch duct system in LBNL laboratory

\section{LABORATORY TEST RESULTS FOR COMMERCIALLY AVAILABLE DEVICES}

\section{Single-Branch Laboratory Test Results for Commercially Available Devices}

Flow Horn 1: This small flow horn has a rectangular opening $(318 \mathrm{~mm} \times 124 \mathrm{~mm}, 12.5 \mathrm{in} \times 4.8 \mathrm{in})$ that fits over the grille and directs the flow over an anemometer placed in the center of a $100 \mathrm{~mm}(4 \mathrm{inch})$ diameter round exit opening. On the single branch system, the flow horn reduced the flow from $52 \mathrm{~L} / \mathrm{s}$ to $33 \mathrm{~L} / \mathrm{s}(110 \mathrm{cfm}$ to $69 \mathrm{cfm})$ for the open duct without a grille, and from $52 \mathrm{~L} / \mathrm{s}$ to $38 \mathrm{~L} / \mathrm{s}(111 \mathrm{cfm}$ to $81 \mathrm{cfm})$ for a system with a grille in place. This $30 \%$ to $40 \%$ reduction in measured flow illustrates the large flow resistance provided by the flow horn. The indicated flow horn readings were $49 \mathrm{~L} / \mathrm{s}$ and $42.5 \mathrm{~L} / \mathrm{s}(103 \mathrm{cfm}$ and $90 \mathrm{cfm})$ for these two cases. This result indicates that the flow horn does not attempt to measure the actual flow through the flow horn, but has been calibrated to attempt to estimate the flow without the horn in place (i.e., the calibration attempts to account for insertion losses). However, the flow horn still under-estimates the airflow by $7 \%$ to $10 \%$, probably because the device it was calibrated on had a different pressure-flow relationship than the one we are using and because of the flow non-uniformities generated by the boot and grille.

It should be noted that attempts to account for insertion losses though calibration only work if the flow being studied has the same pressure-flow relationship as the calibration facility. In particular, calibrations are typically performed on single branch systems in which all the flow is forced to go through every element of the system. In multi-branch systems (essentially all heating and cooling systems), the flow resistance added to one branch redirects the flow through other branches in the system. This results in much larger flow changes through the grille being measured and the calibration would not be able to account for this effect. Flow Horn 1 was used on a couple of grilles on the multi-branch system and the under-predictions of flow were so large (on the order of 50\%) that no further multi-branch tests were performed. We concluded that this device is unsuitable for measuring airflows in multi-branch systems.

Flow Hood 1: This flow hood was tested on the single branch system with no grille, a residential grille (the one-way-throw grille in Figure 4), and a commercial $610 \mathrm{~mm} \times 610 \mathrm{~mm}(2 \mathrm{ft} \times 2 \mathrm{ft})$ grille with its own diffuser (3/16" holes, 1/4" on center). Three flow hood locations over the grille were examined with the grille: centered, in the corner, and in the center of one edge of the flow hood.. In addition, a diffuser screen inserted into the flow capture hood was evaluated to examine its ability to reduce sensitivity to placement issues. The diffuser screen is a piece of woven material that covers the inlet of the flow hood. Lastly, tests were repeated with the edges of the flow hood taped to the surface around the grille to remove leakage/bypass effects. Each case was repeated between two and five times to determine repeatability effects represented by a calculation of RMS. For the commercial system grille only individual measurements were made, except for the nominal $1501 / \mathrm{s}(320 \mathrm{cfm})$ flow rate where the test was done twice. Note that the reference measurements were made with the flow hood in place so the single branch results do not include flow reduction due to the insertion losses.

The results in Table 2 show that the flow hood over-predicted the flow for the residential grilles and underpredicted for the commercial grille. In particular, with corner placement for the no-grille case, the standard operating method over-predicted by almost $50 \%$; this error was reduced to less than $10 \%$ when the diffuser screen was used. Although it is not normal practice to have no grille, the no-grille tests are an indictor of sensitivity to nonuniform flows entering the flow hood. The small difference between the mean difference and RMS difference in each case indicates that these results are biases rather than repeatability errors. 
Table 2. Flow Hood 1, Single Branch Results

\begin{tabular}{|c|c|c|c|c|}
\hline Grille & $\begin{array}{l}\text { Flow Hood } \\
\text { Location }\end{array}$ & $\begin{array}{l}\text { Reference Flow } \\
\text { L/s (cfm) }\end{array}$ & $\begin{array}{l}\text { Mean Difference } \\
\text { L/s (cfm) }\end{array}$ & $\begin{array}{l}\text { RMS Difference } \\
\text { L/s (cfm) }\end{array}$ \\
\hline \multirow{3}{*}{ No grille } & Centered & $52(110)$ & $5(11)$ & $7(15)$ \\
\hline & Corner & $53(112)$ & $23(49)$ & $23(49)$ \\
\hline & Centered Edge & $53(113)$ & $8(18)$ & $9(19)$ \\
\hline \multirow{3}{*}{ No grille } & $\begin{array}{l}\text { Centered, with } \\
\text { diffuser screen }\end{array}$ & $51(108)$ & $4(8)$ & $4(8)$ \\
\hline & $\begin{array}{l}\text { Corner, with } \\
\text { diffuser screen }\end{array}$ & $52(111)$ & $3(7)$ & $3(7)$ \\
\hline & $\begin{array}{l}\text { Centered Edge, } \\
\text { with diffuser } \\
\text { screen }\end{array}$ & $53(112)$ & $4(8)$ & $4(8)$ \\
\hline \multirow{3}{*}{$\begin{array}{l}\text { Residential grille } \\
\text { (damper fully open), } \\
\text { edges sealed }\end{array}$} & Centered & $50(107)$ & $1(1)$ & $1(1)$ \\
\hline & Corner & 49 (104) & $2(4)$ & $2(5)$ \\
\hline & Centered Edge & $50(106)$ & $1(2)$ & $1(3)$ \\
\hline \multirow{5}{*}{$\begin{array}{c}\text { Commercial grille, } \\
2 \mathrm{ft} \times 2 \mathrm{ft}\end{array}$} & Centered & $52(110)$ & $-1(-2)$ & - \\
\hline & Centered & $150(320)$ & $-8(-17)$ & - \\
\hline & Centered & $149(318)$ & $-11(-24)$ & - \\
\hline & $\begin{array}{l}\text { Centered, } \\
\text { edges sealed }\end{array}$ & $148(315)$ & $-2(-5)$ & - \\
\hline & $\begin{array}{c}\text { Centered, } \\
\text { edges sealed }\end{array}$ & 75 (159) & $-1(-1)$ & - \\
\hline
\end{tabular}

Flow Hood 2: This flow meter has two different hood sizes: small $410 \mathrm{~mm} \times 410 \mathrm{~mm}(16$ " $\times 16$ ") and large 610 $\mathrm{mm} \times 610 \mathrm{~mm}(24$ " $\times 24$ "). The manufacturer recommends using the hood that most closely matches the grille size. This device also has a set of vents that are intended to be opened to extend the measurement range to higher flows. The grille used for these tests has vanes to direct the air. Therefore, we first tested the flow hood with it placed so that the air was directed toward the side of the flow hood nearest the grille, and then we tested the hood with it placed so that the air was directed toward the side of the flow hood farthest from the grille. The one-way-throw grille in Figure 4 was used with its damper vanes in the fully open position. As with Flow Hood 1, the tests were repeated several times to examine repeatability issues, and this flow hood was tested in some cases with a diffuser screen. Note that the reference measurements were made with the flow hood in place so the single branch results do not include flow reduction due to the insertion losses.

The results summarized in Table 3 show that the mean and RMS differences are within $0.5 \mathrm{~L} / \mathrm{s}(1 \mathrm{cfm})$ of each other. This is because the experimental results gave consistent biases with little sample-to-sample variation, indicating good repeatability. The remaining single branch tests with the vents open had unstable readings, so in Table 4 an approximate range of readings is given rather than an RMS value. With the vents closed, the diffuser screen approximately halved the measurement errors from about $7 \%$ to $3.5 \%$. Including the results in Table 4 , with the vents open and a higher flow rate, the diffuser screen improved the measurements, with the exception of the centered edge case, where the diffuser screen equipped flow hood significantly under-predicted the airflow. In this case, there was visible fluttering of the flow hood material indicating significantly non-uniform flow inside the flow hood. Repeating the tests with the smaller hood gave similar results, with the diffuser screen giving reduced biases and variability: with the air directed to the near panel, the errors were reduced from $22 \%$ to $3 \%$, and from $14 \%$ to $2.5 \%$ with the air directed to the far panel. 
Table 3. Flow Hood 2, Single Branch Results

\begin{tabular}{|c|c|c|c|c|c|c|}
\hline $\begin{array}{l}\text { Flow Hood } \\
\text { Location }\end{array}$ & Direction & $\begin{array}{c}\text { Hood } \\
\text { Size }\end{array}$ & Vents & $\begin{array}{l}\text { Reference } \\
\text { Flow } \\
\text { L/s (cfm) }\end{array}$ & $\begin{array}{c}\text { Mean } \\
\text { Difference } \\
\text { L/s (cfm) }\end{array}$ & $\begin{array}{c}\text { RMS } \\
\text { Difference } \\
\text { L/s (cfm) }\end{array}$ \\
\hline Centered & \multirow{3}{*}{$\begin{array}{l}\text { Directed to } \\
\text { near panel }\end{array}$} & \multirow{3}{*}{ large } & \multirow{3}{*}{ closed } & 51 (109) & $-2(-5)$ & $2(5)$ \\
\hline Corner & & & & $51(109)$ & $-4(-10)$ & $4(10)$ \\
\hline Centered Edge & & & & $51(109)$ & $-3(-7)$ & $3(7)$ \\
\hline $\begin{array}{c}\text { Centered, } \\
\text { with screen }\end{array}$ & \multirow{3}{*}{$\begin{array}{l}\text { Directed to } \\
\text { near panel }\end{array}$} & \multirow{3}{*}{ large } & \multirow{3}{*}{ closed } & $51(109)$ & $-1(-2)$ & $1(2)$ \\
\hline $\begin{array}{c}\text { Corner, } \\
\text { with screen }\end{array}$ & & & & $51(109)$ & $-3(-6)$ & $3(6)$ \\
\hline $\begin{array}{c}\text { Centered Edge, } \\
\text { with screen }\end{array}$ & & & & $51(109)$ & $-2(-3)$ & -1 \\
\hline $\begin{array}{c}\text { Centered, } \\
\text { with screen }\end{array}$ & \multirow{3}{*}{$\begin{array}{l}\text { Directed to } \\
\text { near panel }\end{array}$} & \multirow{3}{*}{ large } & \multirow{3}{*}{ open } & $123(262)$ & $-4(-9)$ & $4(9)$ \\
\hline $\begin{array}{c}\text { Corner, } \\
\text { with screen }\end{array}$ & & & & $118(250)$ & $1(2)$ & $1(2)$ \\
\hline $\begin{array}{c}\text { Centered Edge, } \\
\text { with screen }\end{array}$ & & & & $118(251)$ & $-12(-25)^{2}$ & $12(25)$ \\
\hline
\end{tabular}

1- No RMS - single reading

2- Edge placement had visible fluttering of the flow capture hood fabric

Table 4. Flow Hood 2, Single Branch Results (cases with unstable readings)

\begin{tabular}{|c|c|c|c|c|c|c|}
\hline $\begin{array}{l}\text { Flow Hood } \\
\text { Location }\end{array}$ & Direction & $\begin{array}{c}\text { Hood } \\
\text { Size }\end{array}$ & Vents & $\begin{array}{l}\text { Reference Flow } \\
\text { L/s (cfm) }\end{array}$ & $\begin{array}{c}\text { Mean } \\
\text { Difference } \\
\text { L/s (cfm) }\end{array}$ & $\begin{array}{l}\text { Variability } \\
\text { L/s (cfm) }\end{array}$ \\
\hline Center & \multirow{3}{*}{$\begin{array}{l}\text { Directed to } \\
\text { near panel }\end{array}$} & \multirow{3}{*}{ large } & \multirow{3}{*}{ open } & $119(253)$ & $5(10)$ & $9(20)$ \\
\hline Corner & & & & $117(248)$ & $9(20)$ & $7(14)$ \\
\hline Centered Edge & & & & $116(249)$ & $3(6)$ & $10(20)$ \\
\hline Center & \multirow{3}{*}{$\begin{array}{l}\text { Directed to } \\
\text { near panel }\end{array}$} & \multirow{3}{*}{ small } & \multirow{3}{*}{ open } & $122(259)$ & $21(45)$ & $9(20)$ \\
\hline Corner & & & & $118(250)$ & $31(65)$ & $10(20)$ \\
\hline Centered Edge & & & & $118(250)$ & $21(45)$ & $9(20)$ \\
\hline $\begin{array}{c}\text { Center, } \\
\text { with screen }\end{array}$ & \multirow{3}{*}{$\begin{array}{l}\text { Directed to } \\
\text { near panel }\end{array}$} & \multirow{3}{*}{ small } & \multirow{3}{*}{ open } & $119(252)$ & $-2(-3)$ & $2(6)$ \\
\hline $\begin{array}{c}\text { Corner, } \\
\text { with screen }\end{array}$ & & & & $111(237)$ & $8(17)$ & $3(6)$ \\
\hline $\begin{array}{l}\text { Centered Edge, } \\
\text { with screen }\end{array}$ & & & & $113(240)$ & $6(12)$ & $4(8)$ \\
\hline Center & \multirow{3}{*}{$\begin{array}{l}\text { Directed to } \\
\text { far panel }\end{array}$} & \multirow{3}{*}{ small } & \multirow{3}{*}{ open } & $118(251)$ & $23(49)$ & $11(24)$ \\
\hline Corner & & & & $119(253)$ & $-2(-3)$ & $5(10)$ \\
\hline Centered Edge & & & & $119(253)$ & $-5(-11)$ & $4(8)$ \\
\hline $\begin{array}{c}\text { Center, } \\
\text { with screen }\end{array}$ & \multirow{3}{*}{$\begin{array}{l}\text { Directed to } \\
\text { far panel }\end{array}$} & \multirow{3}{*}{ small } & \multirow{3}{*}{ open } & $117(249)$ & $-4(-8)$ & $3(6)$ \\
\hline $\begin{array}{c}\text { Corner, } \\
\text { with screen }\end{array}$ & & & & $115(244)$ & $-4(-8)$ & $4(8)$ \\
\hline $\begin{array}{c}\text { Centered Edge, } \\
\text { with screen }\end{array}$ & & & & $115(245)$ & $-2(-3)$ & $3(6)$ \\
\hline
\end{tabular}

\section{Multi-Branch Laboratory Test Results for Commercially Available Devices}

The multi-branch laboratory system was used on two separate occasions. In the first round of testing, three flow capture devices were evaluated and, in some cases, not all grilles were tested due to time limitations. In the second round of testing, five flow hoods were evaluated, including Flow Hoods 1 and 2 from the first round. These two 
retested hoods were the same model and manufacturer as in the first round, but had different production numbers. In the following test results, the mean difference is an indicator of the bias of the flow hood for the combination of tested registers; the RMS difference indicates how well an individual grille is measured. In general, the bias errors are of most interest in this study. The fractions (\%) are the average of the individual fractional errors, not the average or RMS divided by the average grille flow. In most cases, these different methods of calculating fractional differences are extremely close for these data.

Flow Horn 2, Round One: This flow horn is considerably larger than Flow Horn 1, with an inlet of $610 \mathrm{~mm} \times$ $220 \mathrm{~mm}(24 \mathrm{in} \times 8.5 \mathrm{in})$ and a round exit with a $200 \mathrm{~mm}(8 \mathrm{in})$ diameter. Flow Horn 2 was used to measure the flows on the multi-branch system only. The air handler flow was continuously monitored during the tests and there was no measurable change in total system flow when this flow horn was placed over a grille $(<0.5 \mathrm{~L} / \mathrm{s}$ out of $548 \mathrm{~L} / \mathrm{s}$ ,$<1 \mathrm{cfm}$ out of 1,160 cfm). Each grille was measured with the flow horn centered over the grille and then with the grille at the corner of the flow horn inlet. In each case, the flow measurements were averaged for ten seconds, and five separate ten-second averages were recorded. These multiple measurements showed that the repeatability for this instrument was good, with standard deviations of about 1 to $2 \%$ of flow $(0.5 \mathrm{~L} / \mathrm{s}$ to $1 \mathrm{~L} / \mathrm{s}, 1$ to $2 \mathrm{cfm})$ for the five readings at each register. Compared to the reference active flow hood, this flow hood showed a bias of $-3 \mathrm{~L} / \mathrm{s}(-6$ $\mathrm{cfm})$ and an RMS difference of $5 \mathrm{~L} / \mathrm{s}(10 \mathrm{cfm})$. Expressed as fractions of individual grille flow, these correspond to about $-6 \%$ and $10 \%$ of grille flow.

The comparison of the flows measured with the flow hood centered over the grille and with the grille in the corner of the inlet showed a mean difference of $0.7 \mathrm{~L} / \mathrm{s}(2 \mathrm{cfm})$, with the corner placement giving higher readings. The RMS difference between the two placements was $4 \mathrm{~L} / \mathrm{s}(8 \mathrm{cfm})$, or about $8 \%$ of measured flow. These results show that although placement of the flow horn is not critical for total flows, its placement for determining individual grille flows has a significant effect.

Flow Hood 1, Round One: The tests on the multi-branch system were performed with the diffuser screen in place and with the flow hood located in three different positions: carefully centered over each grille, with the grille in one corner and with the grille in the center of one edge of the flow hood. For the 11 grilles of the multi-branch system, the mean error was $0.5 \mathrm{~L} / \mathrm{s}(1 \mathrm{cfm}, 1 \%)$ and the RMS error was $2.5 \mathrm{~L} / \mathrm{s}(5 \mathrm{cfm}, 5 \%)$. These results show how the use of a diffuser screen combined with careful placement can give good results for this flow hood. Further tests were performed on four grilles of the multi-branch system with and without the diffuser screen in place. The mean error with the screen was $-0.5 \mathrm{~L} / \mathrm{s}(-1 \mathrm{cfm},-1 \%)$; without the screen, the mean error was $7 \mathrm{~L} / \mathrm{s}(14 \mathrm{cfm}, 14 \%)$. Similarly, the RMS errors increased from $2 \mathrm{~L} / \mathrm{s}(4 \mathrm{cfm}, 4 \%)$ to $8 \mathrm{~L} / \mathrm{s}(17 \mathrm{cfm}, 17 \%)$ when the diffuser screen was removed. These results that show that the diffuser screen makes the flow hood less sensitive to placement over the grille and improves accuracy.

Flow Hood 2, Round One: Flow hood 2 has two capture hoods of different sizes that are selected based on the size of the register being measured. The larger hood is sized to fit over commercial registers while the smaller hood is recommended for use on residential registers. In this round of testing, Flow Hood 2 was used on only four grilles. Using the smaller hood, the flows were under-predicted by $1.5 \mathrm{~L} / \mathrm{s}(4 \mathrm{cfm}, 4 \%)$, with an RMS error of $4 \mathrm{~L} / \mathrm{s}(9 \mathrm{cfm}$, $9 \%$ ). These tests were repeated using a diffuser screen and the under-predictions were significantly increased to 6 $\mathrm{L} / \mathrm{s}(13 \mathrm{cfm}, 13 \%)$, with an RMS error increased to $7 \mathrm{~L} / \mathrm{s}(15 \mathrm{cfm}, 15 \%)$. In the future, it may be possible to reduce the diffuser screen induced biases through recalibration (note that Flow Hood 1 used a different calibration when the diffuser screen was in place). With the large hood it over-predicted the flows for the four grilles tested by $0.5 \mathrm{~L} / \mathrm{s}(1$ $\mathrm{cfm}, 1 \%)$, with an RMS error of $2 \mathrm{~L} / \mathrm{s}(5 \mathrm{cfm}, 5 \%)$.

Flow Hoods 1 through 5, Round Two: The test results for this second round of testing are summarized in Table 5. The biases range from $1 \%$ to $9 \%$, and the RMS errors from $3 \%$ to $11 \%$. Note that the RMS errors are the average of individual fractions and no the total RMS error divided by the total flow. The diffuser screen used with Flow Hood 1 is again shown to have significant benefits, particularly for individual grille measurements. In all cases, these flow hoods have lower biases than RMS errors indicating that they sometimes over-predict and other times under-predict for an individual grille.

The effect of flow hood position was evaluated by measuring the flows with the grilles centered and then located in one corner of the flow hood. Although the grilles in this system provide a fairly uniform exit flow, this test should still give an indication of flow hood positioning sensitivity. This is a critical issue in residential testing because the furniture and other house fittings (including intersections of walls, floors, and ceilings) often prevent proper centering of a flow hood. The results showed that the difference between a properly centered flow hood and a non-centered one are about $2 \%$ to $5 \%$. Although these are not particularly large errors, in several cases, the majority of the difference was due to significant variations for just a few of the eleven grilles. This indicates that it is more critical to have good centering if one is interested in individual grille flow measurements. 
Table 5. Multi-branch Test Results for Commercial Flow Hoods

\begin{tabular}{|c|c|c|c|c|c|c|}
\hline & $\begin{array}{c}\text { Hood 1 } \\
\text { L/s (cfm) }\end{array}$ & $\begin{array}{c}\text { Hood 1 + diffuser } \\
\text { screen } \\
\text { L/s (cfm) }\end{array}$ & $\begin{array}{c}\text { Hood 2 (small } \\
\text { hood) } \\
\text { L/s (cfm) }\end{array}$ & $\begin{array}{c}\text { Hood 3 } \\
\text { L/s (cfm) }\end{array}$ & $\begin{array}{c}\text { Hood 4 } \\
\text { L/s (cfm) }\end{array}$ & $\begin{array}{c}\text { Hood 5 } \\
\text { L/s (cfm) }\end{array}$ \\
\hline $\begin{array}{c}\text { Mean } \\
\text { Difference }\end{array}$ & $\mathbf{3 ( 7 )}$ & $-1.5(-3)$ & $-5(-10)$ & $1(2)$ & $-0.5(-1)$ & $-3(-6)$ \\
{$[6 \%]$} & {$[-3 \%]$} & {$[-9 \%]$} & {$[2 \%]$} & {$[-1 \%]$} & {$[-6 \%]$} \\
\hline RMS & $4(8)$ & $3(6)$ & $6(12)$ & $1.5(3)$ & $5(11)$ & $3(7)$ \\
Difference & {$[11 \%]$} & {$[5 \%]$} & {$[9 \%]$} & {$[3 \%]$} & {$[9 \%]$} & {$[8 \%]$} \\
\hline \multicolumn{7}{|c|}{ Corner to center differences } \\
\hline Mean & $\mathbf{2 ( 4 )}$ & $-0.5(-1)$ & $1(2)$ & $1.5(3)$ & $-0.5(-1)$ & $0(0)$ \\
Difference & {$[3 \%]$} & {$[1 \%]$} & {$[2 \%]$} & {$[(2 \%]$} & {$[1 \%]$} & {$[0 \%]$} \\
\hline RMS & $3(7)$ & $1.5(3)$ & $1(2)$ & $3(6)$ & $4(9)$ & $1(2)$ \\
Difference & {$[5 \%]$} & {$[2 \%]$} & {$[2 \%]$} & {$[4 \%]$} & {$[5 \%]$} & {$[2 \%]$} \\
\hline
\end{tabular}

\section{FIELD EVALUATION OF COMMERCIALLY AVAILABLE FLOW HOODS ON COMMERCIAL GRILLES}

In previous LBNL studies (Walker et al. 2001 and Wray et al. 2002), commercially available flow hoods were field tested on a residential system. The results of those tests showed considerable differences between different flow hoods. In the current study, we wanted to see if the same differences are also present when testing commercial grilles. We carried out field tests on four different multi-branch subsections of a large VAV system, using one supply grille on each section (there were two to five grilles for any one subsection). We selected four grilles to cover a range of nominal grille airflows from 50 to $200 \mathrm{~L} / \mathrm{s}(100$ to $400 \mathrm{cfm})$. The grilles were all $2 \mathrm{ft}$ square, 4-way throw, with a perforated face (3/16" holes, $1 / 4 "$ on center). The VAV system was set to provide constant flow during the test period (supply air handler at full flow, all VAV box primary air dampers wide open, system set to full recirculation). On each grille, all five hoods were used in sequence with 2' x 2' capture hoods to measure the flows. The reference flow for each grille was measured using the active hood. Manufacturer's instructions for hood operation were followed in each case (e.g., the use of relief vents or low-flow plates). We found that it was essential to follow instructions properly because it was easy to use the wrong operating mode and get large errors (e.g., we found an error of $38 \%$ by using incorrect vent modes for one of the flow hoods).

The results of these field tests are summarized in Table 6. Overall Flow Hood 1 had the best performance with bias and RMS errors less than 2\%. This RMS difference is close to the accuracy of the active flow hood itself, which shows that for this grille type, Flow Hood 1 can give the same results as our reference device within the uncertainty specification of the reference. Flow Hoods 3 and 5 were a little worse, with RMS errors approaching 5\%. Flow Hoods 2 and 4 exhibited significant biases and under-predicted flows by more than $10 \%$.

Table 6. Summary of field test results for commercially available flow hoods on commercial grilles

\begin{tabular}{|c|c|c|c|c|}
\hline Flow Hood & Bias Error, L/s (cfm) & Bias Error, \% & RMS Error, L/s (cfm) & RMS Error, \% \\
\hline 1 & $1(3)$ & 1 & $2(4)$ & 2 \\
\hline 2 & $-14(-29)$ & -11 & $17(36)$ & 11 \\
\hline 3 & $6(12)$ & 4 & $7(15)$ & 5 \\
\hline 4 & $-9(-20)$ & -11 & $10(21)$ & 14 \\
\hline 5 & $-3(-7)$ & -2 & $6(12)$ & 4 \\
\hline
\end{tabular}




\section{LABORATORY TEST RESULTS FOR NEW TECHNIQUES}

\section{Single-Branch Laboratory Test Results for New Techniques}

Basket Hood: For the basket hoods, the grille type (including a no-grille configuration) only changes the results by about $1 \%$ for the three baskets with the smallest open areas. For the other two more open baskets, one had an accuracy of $\pm 3 \%$ for one-, two-, and three-way grilles and under-predicted the flow by about $5 \%$ for the 4 -way grille that introduces swirl into the flow. These errors were reduced to less than $1 \%$ if a honeycomb flow straightener was added to the entry of the basket. The other more open basket had similar results for 1 and 2 -way grilles ( $<3 \%$ error), but gave errors of about $10 \%$ for three- and four-way grilles.

Because these basket hoods are essentially a set of sharp edged holes in parallel, we investigated the possibility of using the open hole area in a standard orifice equation. In practice, many potential users will not have access to calibration facilities, but will be able to measure the area of the holes. In that case, if we can provide a recommended value of orifice coefficient, then a basket with any size hole can be used without needing individual basket calibrations. We measured the open hole area for all the basket hoods. Then, a normalized calibration coefficient was calculated by dividing the calibration results by the open area. We found that using a single value of orifice coefficient of 0.7 gave only a $2 \%$ bias averaged over all five baskets. However, for individual baskets the errors are larger, with an RMS error due to using a fixed value of orifice coefficient of $10 \%$. This result indicates that using a fixed orifice coefficient of 0.7 will produce acceptable results for most potential applications.

The return basket hood was tested on the single return of the multi-branch system, essentially making it a single return branch test. The test results showed that the insertion losses were about $0.5 \%$ (about the same as the accuracy of the reference measurements) and the errors due to non-centering of the flow hood were about $1 \%$. Typical return basket hood pressure drops are about $5 \mathrm{~Pa}$, and additional testing needs to be performed on systems with multiple large returns to see if these insertion losses produce significant errors.

Bag Filling: We calibrated the bags that we tested using the single branch system without a grille to determine the effective volume and the time exponent. As with the basket hoods, the single branch tests of the bags were also used to assess the sensitivity of the bags to different grilles. We tested five different sized bags using this procedure. The first two bags were commercially available garbage bags that we had in our laboratory. The other three bags were purchased from a hardware store. Because we have the original packaging for these latter three bags, we know the nominal volume claimed by the manufacturer. If bags are to be used by a wide range of people who do not have access to calibration facilities, then we need to know the accuracy of measured airflows if the user relies upon information they are likely to have: i.e., the nominal volume $(V)$ based on package labeling. Assuming a time $(t)$ exponent of -1 allows us to use Equation 1 to determine the air flow $(Q)$.

$$
Q=V t^{-1}
$$

We found that the calibrated bag volume for Bag 3 seemed to be significantly larger than the nominal volume. However, it was difficult to determine how much larger the effective volume was with this bag, because the material of the bag was too lightweight to obtain uniform bag filling. This led to the bag folding over onto itself and the bag would only partially fill resulting in additional uncertainty about its calibration. Bags 4 and 5 were constructed from a heavier gauge of plastic film and did not have this problem. For Bag 5, the calibrated volume was very close to the nominal value (within 2.5\%); for Bag 4, the difference was $12.5 \%$. At a typical register flow of about $50 \mathrm{~L} / \mathrm{s}(100$ $\mathrm{cfm}$ ) using the nominal volume and fixed time exponent of -1 led to overpredictions of $5 \%$ and $10 \%$ respectively for bags 4 and 5 .

We also tested all five bags with the various grilles shown in Figure 4. For the one-way-throw grille, the results were within $5 \%$ of the calibration. However, for the three-way-throw grille at higher flows $(>50 \mathrm{~L} / \mathrm{s}, 100 \mathrm{cfm})$, the errors increase to about $10 \%$ for Bags 1 and 2 . The problem is that the bags inflate only on one side so that they never fully fill up, and it is difficult to visually determine when the bags are full with this highly direction grille flow. We performed additional tests with the grille dampers inclined at large angle, and found the same problem.

Because the wooden frame for the bag entry is unlikely to be used by homeowners, we also tested Bag 1 with a wire frame made from a coat hanger (as recommended in the CMHC literature referenced earlier). We experimented by bending the coat hanger into different opening shapes to see if the results were affected by opening shape. This is important for a couple of reasons: first, users may not be able to create a uniform opening and we need to know how much uncertainty this creates, and second, some grilles in houses are odd shapes and the flexibility of the frame is then useful because it allows the user to completely cover each grille. We tested eight opening shapes, using three different grilles: the two-, three-, and four-way-throw grilles shown in Figure 4. We found that for the two-way 
grille, the results are not very sensitive to the shape of the bag opening. However, for the three-way grille, there are significant differences $(>5 \%)$, probably due to the more non-uniform flow directions exiting this grille.

\section{Multi-Branch Laboratory Test Results for New Techniques}

Supply Basket Hoods: We found that the basket hoods significantly under-predicted the multi-branch system flows due to insertion losses: typically by about $20 \%$ for a $5 \mathrm{~Pa}$ basket pressure difference to $60 \%$ at higher pressures. We examined two potential correction methods for accounting for these insertion losses: single point and two-point. The single point correction is empirical and is based on measurements on the multi-branch laboratory system, as well as on tests in three houses from a previous study (Sherman and Walker 2002). The two-point correction uses two baskets of different flow resistances combined with analytical and empirical correction terms. A total of 88 grille flows from eight houses and the multi-branch laboratory apparatus were used to determine the correction factors. Not all grilles were tested with all the baskets; therefore, different subsets of these 88 measurements were used for each correction evaluation.

The single point correction uses Equation 1, with the value of $k$ determined from the field and laboratory measurements.

$$
Q_{\text {correct }}=Q_{\text {calibration }}(1+k \Delta P)
$$

where

$\mathrm{Q}_{\text {correct }}$ is the true flow measured using the reference flow meter and

$\mathrm{Q}_{\text {calibration }}$ is the flow rate calculated using the hood calibration.

The value of $k$ ranged from 0.03 to 0.09 depending on which of the five tested baskets was being evaluated, and whether the honeycomb flow straightener had been used. Using a single value of $k=0.055$ results in bias errors less than 3\% and RMS errors of about a $10 \%$. These results indicate that using a single value for $k$ gives reasonable results for most flow hood applications. The results also showed that this single point correction works most reliably for flow hoods that have low flow resistance. For example, restricting the application of Equation 2 to a single low flow resistance flow meter resulted in a value of $k=0.045$, with a bias less than $1 \%$.

Sherman and Walker (2002) gave the details of how to develop the functional form required for multi-point extrapolation. This relationship was developed for a two-branch system and analysis for more branches tends to add complexity without improving flow estimates because of the additional unknowns that each branch brings to the analysis. The two point testing was only investigated in detail for a subset of 34 of the grilles. Equation 3 includes empirical velocity pressure corrections and is used to calculate the corrected flow based on the two flowmeter flows and pressures: the subscript "lo" refers to low flow resistance (so high flow and low pressure difference) and "hi" is for high flow resistances.

$$
Q_{\text {corrected }}=Q_{l o}+\frac{\left(Q_{l o}-Q_{h i}\right)\left(\Delta P_{l o}-k_{2} \Delta P_{l o}\right)^{0.5}}{\left(\Delta P_{h i}-k_{2} \Delta P_{l o}\right)^{0.5}-\left(\Delta P_{l o}-k_{2} \Delta P_{l o}\right)^{0.5}}
$$

Using Equation 3 with the two-point correction factor, $k_{2}$, equal to 0.67 (determined by trial and error to minimize biases) reduced biases to $-0.1 \%$ and the RMS errors to $7 \%$ (i.e., about the same improvement as the simple linear empirical relationship). The reason for this is a combination of random uncertainty in the measurements, and the variation in individual branch flow resistance for each grille that cannot be easily taken into account.

Bag Filling: Bags 1 and 2 were tested on each of the 11 multi-branch laboratory system grilles three times in order to study both the accuracy compared to the reference flow hood and the repeatability of the results. The bias is less than $1 \%$ for Bag 2 and only $4 \%$ for Bag 1 . This indicates that these bags have sufficient accuracy for all applications using the sum of grille flows (total fan flow and duct leakage). The RMS errors are a little larger at $5 \%$ to $7 \%$, but are still accurate enough for any diagnostic requiring individual grille measurements to be known. The repeatability uncertainties averaged about $3 \%$ for these two bags on this system. These good results (compared to the errors found earlier looking at highly directed flows out of individual grilles) are partly due to the relatively uniform flow out of the grilles used for the multi-branch testing.

\section{FIELD EVALUATION OF NEW TECHNIQUES}

Commercial Supply Basket Hood: We field-tested the commercial supply basket hood on 11 grilles in three small commercial building systems. The reference flow hood for the grille flows was the same active flow hood used for the residential field tests. Our test results showed that basket hood errors were mostly biases: they tend to 
under-predict the flows, with a mean difference of $-12 \%(31 \mathrm{~L} / \mathrm{s}(66 \mathrm{cfm})$ and an RMS difference of $15 \%(40 \mathrm{~L} / \mathrm{s}$ $(85 \mathrm{cfm})$. In addition, the under-prediction is greater (up to $25 \%(78 \mathrm{~L} / \mathrm{s}(167 \mathrm{cfm}))$ ) at higher flow rates, when the backpressure of the flow hood is highest (almost $30 \mathrm{~Pa}$ for the biggest underprediction). This indicates that the under-prediction is due to the extrapolation of the measured flows to the flow without the flowmeter in place. The same two-point velocity pressure correction technique used for residential grilles (Equation 3 ) was applied to the commercial measurements. Using a two-point correction factor, $k_{2}$, equal to 0.1 , reduced the bias error to $-0.5 \mathrm{~L} / \mathrm{s}$ ($1 \mathrm{cfm}(2 \%))$ and the RMS uncertainty to $23 \mathrm{~L} / \mathrm{s}$ (49 cfm (11\%)).

Return Basket Hood: The return basket hood was calibrated on the multi-branch laboratory system using that system's high accuracy flow nozzle. It was then field tested on five residential and three small commercial buildings. An active flow hood was used as the reference for these tests. The average difference over all these systems was only $-0.2 \%$ and the RMS difference was $2 \%$. This RMS difference is close to the accuracy of the active flow hood itself, which shows that the return basket hood gives the same results as our reference device within the uncertainty specification of the reference.

Bag Filling: Bag 1 was used on thirty grilles in three houses. Compared to the reference flow hood, the bias was $-5 \%$ and the RMS uncertainty was $11 \%$. These results indicate that although the bag filling method appears crude, the results of bag testing can be used for almost all grille airflow diagnostics, with the exception of the requirement for duct leakage estimates (but even for that test, the $5 \%$ bias is very close to being acceptable). We found that the largest errors are for grilles whose flows are lower than about $20 \mathrm{~L} / \mathrm{s}(40 \mathrm{cfm})$. At these small flows, the influence of leakage around the edge of the bag is increased because it takes a long time to fill the bag, and the small backpressure required to fill the bag becomes more significant at the low flow grilles.

Because the bag filling tests require an individual to interpret when the bag filling starts and stops, we need to look at variability from user to user. Five people (including researchers, a homeowner, and their son - none of whom had any previous experience with this measurement technique) measured the same grille in a house three times. Each person was given simple instructions on how to perform the testing and observed an experienced researcher perform the test. The results were that the five averaged flows were in a narrow range between 29 and 30 $\mathrm{L} / \mathrm{s}(61$ and $64 \mathrm{cfm})$. Compared to the reference flow measurement, there was an RMS error of only $1.1 \mathrm{~L} / \mathrm{s}(2.4$ cfm) (4\%).

\section{DISCUSSION}

Based on our test results, flows measured using commercially available flow hoods can vary widely, with some devices performing much better than others. Some devices exhibited enough sensitivity to placement over the grilles and the extremes of flow non-uniformity that their applications are severely limited. Flow Horn 1 in particular produced such large backpressure that it was essentially useless for any branched system. All the tested flow hoods had good repeatability (less than 5\% variability) if well centered over the grille. In general, the results showed that most of the errors are biases rather than random errors. The diffuser screen reduced sensitivity to placement and flow direction, but recalibration may be required to account for the extra insertion loss. The diffuser screen is particularly useful in removing the extreme (on the order of 50\%) errors and reducing them below $10 \%$ for some individual grille measurements. Finally, testing on a small number of commercial grilles shows less variability than for residential applications, mostly because the flow hood size matches the grille size (meaning the hood is well centered) and the tested grilles had built-in diffusers. However, there was still a significant range of biases from 1 to $10 \%$ depending on the individual flow hood, with two of the five being significantly worse than the others. These results indicate that there is the potential for flow hoods to be accurate enough for a wide range of residential HVAC system diagnostic applications, as long as they are well designed to account for the issues of centering and nonuniform flow, and they do not introduce large backpressures. Combined with the observed range of performance on commercial grilles, this implies that standards are needed to ensure consistent and realistic calibration and testing of flow hoods.

The results of the basket hood and bag filling tests are discussed in the context of the lower expectations of these devices compared to commercial equipment. In other words, a $10 \%$ error from bag-filling or an adapted laundry basket is more acceptable than a $10 \%$ error from a much more expensive commercial device because we do not expect the simple home-made device to work as well. The basket hood combines sufficient accuracy for most applications while being cheap and easy to use. The development of the basket hoods has shown that it is important to balance the need to have hoods that introduce small flow resistances with the precision limits of measuring pressures. Extrapolation errors from the intrinsic flow resistance can be effectively reduced by simple empirical correction factors that result in biases of about 3\% and RMS errors of about $10 \%$. Our experience showed that extrapolation should be limited to about a $20 \%$ change in flow for best results. There is a small added uncertainty 
$(<5 \%)$ if we simply measure the hole size and assume an orifice coefficient of 0.7 and use a standard orifice equation rather than specifically calibrating individual devices.

Bag filling is a good method to measure the flows for situations where the necessary accuracy does not have to be better than $10 \%$. The test results showed that the volume indicated by the manufacturer can be used, rather than a sophisticated calibration, and only introduces an additional error of about 5 to $10 \%$.

All these results are based on a limited set of measurements. Future work needs to expand on these evalautions, in particular by performing more field testing of basket hoods and bag filling to confirm their potential as alternative measurement techniques.

\section{ACKNOWLEDGEMENTS}

This work was supported by the Assistant Secretary for Energy Efficiency and Renewable Energy, Building Technologies, of the U.S. Department of Energy under contract No. DE-AC03-76SF00098. The research reported here was also funded by the California Institute for Energy Efficiency (CIEE), a research unit of the University of California, under Contract No. S9902A. Publication of research results does not imply CIEE endorsement of or agreement with these findings, nor that of any CIEE sponsor.

The authors would like to thank Energy Performance of Buildings Group staff and students who contributed to the tests and provided thoughtful guidance for this paper: Darryl Dickerhoff, Duo Wang, Bass Abushakra, Sylvain Masson, and Cyril Guillot.

\section{REFERENCES}

Abushakra, B. A., Walker, I.S., and Sherman, M.H. 2002. "A Study of Pressure Losses in Residential Air Distribution Systems". Proc. ACEEE Summer Study 2002. Vol. 1, pp. 1-14. American Council for an Energy Efficient Economy, Washington, DC. LBNL-49700.

CMHC. 2002. CMHC Garbage Bag Airflow Test http://www.cmhcschl.gc.ca/en/burema/gesein/abhose/abhose_ce46.cfm. Canada Mortgage and House Corporation. Ottawa. Canada.

Choat, E.E. 1999. "Resolving Duct Leakage Claims". ASHRAE Journal, March 1999. pp. 49-53. Atlanta, GA: American Society of Heating, Refrigerating, and Air-Conditioning Engineers, Inc.

Sherman, M.H. and Walker, I.S. 2002. "Residential HVAC and Distribution Research Implementation”. Lawrence Berkeley National Laboratory. Berkeley, CA. LBNL-47214

Walker I.S., Wray, C.P., Dickerhoff, D.J., and Sherman, M.H., 2001 "Evaluation of Flow Hood Measurements for Residential Register Flows". Lawrence Berkeley National Laboratory. Berkeley, CA, LBNL-47382.

Wray, C.P., Walker, I.S., and Sherman, M.H., 2002. "Accuracy of Flow Hoods in Residential Applications". Proc. ACEEE Summer Study 2002. Vol. 1, pp. 339-350. American Council for an Energy Efficient Economy, Washington, DC. LBNL-49697. 